\title{
Una propuesta de recorrido bibliográfico por las migraciones femeninas en España ${ }^{1}$
}

\author{
Gemma Aubarell \\ Institut Català de la Mediterrània \\ Avda. Diagonal, 407, bis, planta 21. 08008 Barcelona. Spain \\ picm0002@correu.gencat.es
}

\section{Resumen}

Este artículo recoge los principales puntos de interés de los que parten una selección de unas cien obras (publicadas o inéditas) aparecidas en España en los últimos diez años sobre el tema de las migraciones femeninas extracomunitarias. A partir del recorrido propuesto, se identificarán algunas de las más relevantes características, así como la evolución temática y metodológica que han seguido estas aproximaciones. Lejos de pretender un sumario exhaustivo o una enumeración meramente bibliográfica, la estructura del artículo y las referencias que en él se incluyen pretenden aportar las claves para situar esta última década de literatura dedicada a la inmigración femenina en España.

Palabras clave: género, migraciones, bibliografía, investigación, España.

\section{Abstract. A bibliographical journey through female migration in Spain}

This article refers to the key points arised from more than 100 works (published or unpublished) on female immigration that have came out in Spain during the last decade. What we propose here is to look over these materials in order to identify the most important characteristics. This essay will allow us to identify the main topics and the major methodological issues arised by researchers. This work does not intend to show an exhaustive directory of bibliography. Our aim is only to help the readers to situate what has been written on the issue of Women's Migration literature during these last ten years in Spain.

Key words: gender, migrations, bibliography, research, Spain.

1. La investigación documental a partir de la cual se ha elaborado este artículo se ha realizado conjuntamente con Elisenda Macià, responsable del servicio de documentación del Institut Català de la Mediterrània. Agradezco asimismo la inestimable colaboración de Natalia Ribas, que con sus comentarios ha enriquecido considerablemente el contenido de este artículo. 


\section{Sumario}
1. Introducción
6. El mercado de trabajo: un eje
2. Algunas claves de partida definitivo de segmentación por género
3. A la búsqueda de datos.
7. La geografía de las migraciones: lugares
Las aproximaciones cuantitativas de recepción y población de origen
4. La generalización de la perspectiva
8. Género e inmigración: tipologías
cualitativa
y perspectivas bibliográficas

5. Contextualización y descripción

\section{Introducción}

Podría considerarse un eufemismo hablar de bibliografía sobre migraciones femeninas en España. Y es que, de hecho, la búsqueda resulta dificultosa en un contexto migratorio cuyas tendencias se están todavía perfilando en estos últimos años. Seguramente coincidiremos con gran parte de los autores y autoras en afirmar que, en el ámbito de los movimientos humanos, el género ha sido menos abordado que en otros campos de las ciencias sociales.

Sin embargo, de ello no podemos deducir que esta falta de atención afecte únicamente al contexto español. Tal y como se apunta en parte de las aproximaciones teóricas al tema, el tratamiento de los movimientos migratorios en Europa (y también en los países de origen) ha tendido generalmente a percibirse desde el punto de vista de la movilidad de la fuerza económica, y tradicionalmente se ha obviado el papel activo de las mujeres, tanto en lo que se refiere a su dinamismo en el interior de las redes migratorias, como a su protagonismo económico. No será hasta bien entrada la década de los años setenta que la mujer inmigrada comenzará a tomar un cierto papel en los análisis de ámbito transnacional, aunque prácticamente siempre desde una perspectiva asociada a los movimientos masculinos. Los años ochenta serán los que reflejarán por primera vez la aparición del género en los procesos migratorios de una manera autónoma. De la literatura sobre el tema podemos deducir que ello es posible gracias, por una parte, a entender la importancia de las redes y estrategias familiares en las migraciones y, por otra, como consecuencia de considerar el papel de la mujer inmigrante como población activa. Ambas características posicionan en un primer momento a la mujer como una actora del proceso migratorio. Más adelante, tal y como podrá comprobarse a través de la bibliografía más reciente, las migraciones femeninas aparecen como una tipología en sí mismas, y la variable género, más allá de la variable sexo, se convierte en un factor de análisis en sí mismo.

Actualmente la realidad nos muestra como el colectivo femenino representa aproximadamente la mitad de la población inmigrante en Europa. En España, como en otros países meridionales de la Unión Europea, este crecimiento ha acompañado las incipientes oleadas migratorias de población extranjera en los últimos años, tal como hemos podido ver a través de los artículos de este monográfico. Efectivamente, los años noventa evidenciarán la presencia, entre la nueva oleada de inmigración extranjera no comunitaria, de población 
femenina que, en el caso de España, afectará muy especialmente a colectivos amplios como el latinoamericano, mientras en algún colectivo específico, como el filipino, supera incluso a los efectivos masculinos, y en otros, como es el caso de la población femenina marroquí, aumentará considerablemente. De ahí el interés de esta última etapa.

Como apuntábamos más arriba, la situación española a propósito del tema que nos ocupa y por ende su reflejo bibliográfico, refleja una situación común en los países meridionales de la UE. Si bien cada país responde a unas características diferenciadas en razón de su propia dinámica migratoria, Grecia, Portugal y sobre todo Italia, comparten con España muchas de las características derivadas de la nueva inmigración femenina y de análisis más o menos reciente de esta situación (véase King y Zontini en este monográfico). Una atenta mirada sobre la bibliografía de estos países, en gran parte de carácter empírico, nos recordará algunos de los temas centrales que más adelante encontraremos en mayor o menor medida reflejados en el caso español.

Destacaremos aquí aquellas características que responderían a un modelo migratorio de la Europa del sur. En primer lugar, es notable el interés que merece la situación laboral y la precariedad en la que se encuentra esta población. La literatura existente refleja el peligro de marginación de las trabajadoras inmigrantes, que en gran parte conforman un ejército de mano de obra con frecuencia irregular, y cuya presencia en el sector terciario es muy importante en todos estos países. Así mismo, la situación de cambio de las propias sociedades receptoras de la Europa meridional y en concreto de la mujer, se toman en consideración para entender también características propias del modelo. Un segmento que está mereciendo la atención de las más recientes publicaciones es el de la prostitución, sus características cada vez más evidentes de marginación y su relación con las redes de extorsión. El análisis por nacionalidades de origen acostumbra, también, a constituir una metodología extendida a la hora de tratar este tema, a la vez que se prioriza la situación en contextos urbanos (descripción, políticas sociales...) en los que abunda la migración femenina.

\section{Bibliografía 1}

Selección de fuentes sobre migración femenina en Grecia, Italia y Portugal ${ }^{2}$

Albuquerque, R. (2000). «Political participation of Luso-African youth in Portugal: some hypothesis for the study of gender». Papers, 60: 167-182.

2. Selección realizada en gran parte a partir de la bibliografía citada por los autores y autoras de este número de PAPERS. Se ha obviado, en este apartado, otras fuentes de bibliografía extranjera que aparecen en revistas como REMIS o algunos de los libros que últimamente se han editado sobre esta cuestión en Inglaterra, como el de F. Ahthias y G. Lazaridis (Gender and Migration in Southern Europe. Women on the move, Oxford: Berg, 2000), o las contribuciones de Ioardinnis Psimmenos (Grecia), Victoria Chell (Italia), Marina Orsini-Jones y Francesca Gatullo (Italia), Jacqueline Andall (Italia), Natalia Ribas-Mateos (España), Ángeles Escrivá (España) y Karen O’Really (España). 
ANDALL, J. (1988). «Catholic and state constructions of domestic workers: the case of Cape Verdean women in Rome in the 1970s». En Koser, K. (ed.). The New Migration in Europe: Social Constructions and Social Realities. Londres: Macmillan, p.124-142.

BARSOTTI, E.; LECCHINI, L. (1995). The experience of Filipino female migrants in Italy en International Migration Policies and the Satuts of Female Migrants. United Nations Expert Group Meeting on International Migration Policies and the Status of Female Migrants. San Miniato, Italia, 28-31 de marzo, 1990. Nueva York: ONU Dep. for Economic and Social Information and Policy Analysis. Population Division.

BOYD, M. (1991). «Donne migranti e politiche di integrazione». En PrESIDENZA Del Consigilio dei Ministri. Atti della Conferenza Internazionale sulle Migrazioni. Roma, p. 619.

CAMPANI, G. (1999). «Immigrant women in Southern Europe: gender, social exclusion and prostitution in Italy». En KING, R. y otros (ed.). Eldorado or Fortress? Migration in Southern Europe. Londres: Macmillan.

Caponio, T.; Nielsen, A.; Ribas, N. (2000). "The policy mirror mechanism": the case of Turin». Papers, 60: 67-83.

Carchedi, F. (2000). "Considerations on foreign prostitution in Italy». Papers, 60: 85-97.

Catarino, C.; Oso, L. (2000). «La inmigración femenina en Madrid y Lisboa: hacia una etnización del servicio doméstico y de las empresas de limpieza». Papers, 60: 183-207.

Chell, V. (1997). "Gender-selective migration: Somalian and Filipo women in Rome». En KInG, R. y otros (ed.). Southern Europe and the New Immmigrations. Brighton: Sussex Academic Press, p. 75-92.

Coop. Soc. Parsec; Università di Firenze, Dipartimento di Scienze DELL'EDUCAZIONE (1996). Il traffico di donne immigrate per sfruttamento sessuale: aspetti e problemi. Ricerca ed analisi della condizione italiana. Rapporto finale per la Conferenza Internazionale di Vienna. Organizzazione Internazionale dell Migrazioni. Roma.

De Benart, M.; Di Pietrogiacomo, L.; Michelini, L. (1995). Migrazioni femminili, famiglia e reti sociali tra il Marocco e l'Italia. Turín: L'Harmattan Italia.

De Filippo, E.; Pugliese, E. (2000). «Le donne nell'immigrazione in Campania». Papers, 60: 55-66.

FAKIOLAS, R.; MARATOU-AliPRANTI, L. (2000). «Foreign female immigrants in Greece». Papers, 60: 101-117.

GIUDICI, C. (1999). «Immigració i procés d'integració a Itàlia». En RoQUE, M. Dona i Migració a la Mediterrània Occidental. Barcelona: Proa.

KING, R.; ZonTINI, E. (2000). «The role of gender in the South European immigration model». Papers, 60: 35-52.

LAZARIDIS, G. (1995). «Female immigrants in Greece. Domestic workers from Philippines and Albania - a field survey». European Forum of Left Feminists Nationalism, Racism and Gender. Thessaloniki: Paratiritis, p. 47-75. 
Orsini-Jones, M.; GatTullo, F. (1995). «Visibility at a price? Black women in Red Bologna». Tuttitalia, 14: 24-38.

Perista, H.; MaCHADO, F. (1997). «Femmes immigrées au Portugal: identités et différences». Migrations-Société, 52(9): 91-103.

PERISTA, H. (2000). «EU migrant women: migration, family life and professional trajectories». Papers, 60: 153-166.

Ribas, N. (2000). «Old communities, excluded women and change in Western Thrace (Thracian Greece, the Provinces of Xanthi, Rhodopi and Evros)». Papers, 60: 119-150.

VALENCIA, D. (1995). «The status of Philipino women in Greece». European Forum of Left Feminists. Athens, Thessaloniki: Paratiritis, p. 79-84.

\section{Algunas claves de partida}

Tradicionalmente, la visibilidad del fenómeno migratorio femenino, sobre todo respecto a las publicaciones y los medios de comunicación en general, pero también y de manera significativa, a nivel conceptual, han sido resultado de unas pautas que, al menos aparentemente, poco han tenido que ver con la realidad. Durante estos últimos años, sin embargo, resulta bastante significativo comprobar el incremento de literatura que aflorará, a medida que el interés por el fenómeno migratorio en general irá tomando una especial consideración.

Desigual y dispersa serían dos de los adjetivos más apropiados para describir los artículos y libros — los menos_-, aparecidos estos últimos años en España. Esta situación en parte se da como resultado de que esta corriente bibliográfica ha sido muy a menudo el resultado de la sensibilización de diferentes agentes e instituciones sociales, y de la propia iniciativa y voluntarismo de algunos de los colectivos en cuestión. De todo ello podríamos deducir que, al mismo tiempo que se ha ampliado el margen de estudio, también se ha subjetivizado el campo de análisis.

En primer lugar, muy relacionado con este aspecto, cabe destacar como parte de la bibliografía aparece como resultado de actividades, jornadas o estudios. Comunidades autónomas, ministerios, institutos de la mujer, corporaciones locales, sindicatos o las propias asociaciones de inmigrantes serán algunas de las instancias que se mostrarán más activas. Como consecuencia de ello, a menudo la sensibilización, de una parte y, de otra, la necesidad de actuaciones para afrontar el problema, se confunden con el requerimiento de evaluar y estudiar la situación. Abundarán informes y actas de jornadas y trabajos, que conforman una interesante literatura gris que permanece sin publicar. Uno de los casos más paradigmáticos, por su calidad y porque se considera ya un referente básico en la bibliografía femenina en España, son las Jornades sobre les Dones Immigrades, organizadas por el Ayuntamiento de Barcelona en 1994 (impulsadas sobre todo desde el CIRD, Centre d'Informació i Recursos per a les Dones). A pesar de su importancia, estas jornadas se recogen en un dossier de ponencias sin editar. Y es que una dificultad añadida en la recopilación 
bibliográfica es la incapacidad de reflejar toda una serie de documentación y literatura gris que la mayor parte de las veces permanece «inédita».

En segundo lugar, otro aspecto fundamental a tener en cuenta es el creciente dinamismo desde el ámbito universitario y de la investigación. En este campo, las publicaciones se han llevado a cabo desde la sociología y la antropología, más que desde otros ámbitos científicos. Cabe señalar la falta de aproximaciones desde disciplinas como la económica o la jurídica, campos que, paradójicamente, crean algunos de los contenciosos más importantes de estos movimientos poblacionales. Efectivamente, desde la perspectiva de la investigación y en el campo de la sociología de las migraciones, contamos con algunos estudios pioneros que, en parte desde las migraciones en general y en parte desde la perspectiva del género, han constituido referentes muy importantes a partir de los cuales abrir nuevos campos de análisis. Desde la antropología otras autoras también han marcado una importante pauta, sobre todo respecto al estudio del género.

Fruto de todos estos primeros esfuerzos, en la segunda mitad de la década asistiremos a la explosión de trabajos de campo y de tesis doctorales que progresivamente van viendo la luz editorial. Y es significativo el protagonismo de Madrid en este sentido. También las universidades de Barcelona, de La Coruña y la Universidad de Granada se muestran especialmente activas en este tipo de análisis. Muy probablemente estas investigaciones constituyan el mejor indicador de las tendencias que se abren para estos próximos años en los estudios sobre migración y género. La diversidad de las aproximaciones y la calidad de sus aportaciones están posicionando toda una corriente de estudios que hasta el momento permanecía virgen. Una vez más, señalaremos como buena parte de estas nuevas investigaciones han sido escritas por mujeres. Diríamos que nos encontramos generalmente ante una marcada feminización del discurso, que en algunos casos viene acompañado por una declarada perspectiva feminista.

\section{Bibliografia 2}

Tesis doctorales (1996-1999)

ESCRIVÁ, Ángeles (1999). Mujeres peruanas en Barcelona. Universitat Autònoma de Barcelona.

GREGORIO GIL, Carmen (1996). Sistemas de género y migración internacional: la emigración dominicana a la Comunidad de Madrid. Universidad Autónoma de Madrid.

Herranz GómeZ, Yolanda (1996). Formas de incorporación laboral de la inmigración latioamericana en Madrid: importancia del contexto de recepción. Madrid. Universidad Autónoma de Madrid.

Oso CASAS, Laura (1998). La migración hacia España de mujeres jefas de hogar. Universidad de A Coruña.

RAMíREZ, Ángeles (1997). Migraciones, género e islam: mujeres marroquies en España. Universidad Autónoma de Madrid. 
RESTREPO, Ofelia (1998). Mujeres colombianas sujetos históricos en una historia de inmigración. Universidad Autónoma de Madrid.

RIBAS, Natàlia (1996). La heterogeneidad de la integración social: una aplicación a la inmigración extracomunitaria (filipina, gambiana y marroquí) en Cataluña (1985-1996). Universitat Autònoma de Barcelona.

Rojo, Aurora (1997). Mujeres marroquies: trayectorias y experiencias vitales. Madrid: Universidad Complutense.

A partir de esta constatación, este breve artículo que se presenta pretende un recorrido a través de los principales puntos de interés de los que parten un centenar de obras aparecidas sobre migraciones femeninas no comunitarias en este país durante la última década. Las referencias bibliográficas pretenden situar la literatura dedicada a la inmigración femenina en España durante los noventa ${ }^{3}$.

En cuanto a la estructuración del artículo, se han tenido en cuenta básicamente dos grandes ejes. En una primera parte se ha agrupado la bibliografía que aporta unas dimensiones sociológicas presentes en los estudios sobre migración en general: la dimensión demográfica (estudios cuantitativos y aproximaciones contextuales), que constituye una premisa analítica a través de la cual se identificará la variable sexo; la geografía de los movimientos poblacionales (los polos de emisión y de recepción de inmigrantes) y la dimensión económica (a través del mercado de trabajo). Estas tres características identifican en un primer momento al sujeto migrante femenino dentro del proceso global, para pasar progresivamente a incorporar aspectos y problemáticas más o menos concretas ligadas al género.

En un segundo apartado, se han escogido aquellos aspectos que aíslan y confieren identidad a las migraciones femeninas respecto a los movimientos poblacionales masculinos, esbozando una tipología de aquellos análisis más propiamente relacionados con el género como factor en sí mismo y agrupados en tres grandes bloques, atendiendo a las temáticas de la bibliografía disponible: Políticas públicas, Representaciones e integración, Identidad y sistemas de género.

Con todo, y si bien el artículo pretende una estructura esclarecedora, las divisiones no son nunca exactas. De hecho, alguna de las publicaciones estará recogida en más de un apartado, mientras que en otros casos se han primado unas características sobre otras. También debe añadirse que la necesidad de

3. La investigación se ha elaborado a partir de las fuentes del centro de documentación del Institut Català de la Mediterrània, procedentes tanto de su fondo bibliográfico, como de sus trabajos y materiales que se han ido recopilando a través de las actividades realizadas sobre este tema. La investigación ha sido completada, también, gracias a la información bibliográfica del Instituto de la Mujer de Madrid, del Institut Català de la Dona de Barcelona y del Centro de documentación del Colectivo IOÉ-Asociación Nexos de Madrid, aportada en el transcurso de la preparación de las jornadas sobre Mujer y migración en el Mediterráneo Occidental, organizadas por el ICM en 1998. 
referenciar apartados y epígrafes claros, ha hecho necesario obviar algunas referencias interesantes, que si bien trataban en su análisis la variable género, no lo hacían a partir de un enunciado o un epígrafe específico. De ahí que el artículo proponga «un recorrido», más que ofrecer listados cerrados. Lejos de comentar los contenidos, el interés es sobre todo el de aportar útiles para aquel lector más interesado en profundizar en uno u otro aspecto. Se ha optado por reflejar la diversidad de los documentos existentes, de ahí que en algunos casos se detallen algunos epígrafes y/o artículos de publicaciones más amplias, a fin de aportar el máximo de información sobre el tema.

\section{A la búsqueda de datos... Las aproximaciones cuantitativas}

La invisibilidad estadística de las mujeres inmigradas ha sido una constante y un aspecto que ha dificultado en gran medida el análisis de este colectivo, debido en gran parte a que, tradicionalmente y hasta hoy, las fuentes disponibles han subestimado, como ya es sabido, su papel. Visibilidad social y borrosidad estadística es la expresión con la que algunos autores explicarían esta aparente contradicción que se arrastra. Existe, sin embargo, una correlación importante entre la aparición de los primeros artículos y el nuevo fenómeno inmigratorio que justo empezaba a perfilarse a finales de los años ochenta. El hecho de no contar con datos por sexo de residentes extranjeros hasta 1992-93 condicionará en gran medida la aparición de estudios específicos hasta aquel momento. Más adelante mucha bibliografía posterior recorrerá a las fuentes secundarias (uso de las infraestructuras sanitarias, nacimientos, servicios sociales...) y también a las estadísticas de los padrones y de los censos.

Podemos afirmar que la primera bibliografía del género en las migraciones extranjeras en España aparece acompañando tímidamente este proceso de afloramiento femenino. Con todo, destacan algunos trabajos en los que se enmarcará la importancia de los flujos femeninos. Sorprende, sin embargo, comprobar como a finales de los ochenta e inicios de los años noventa no existen prácticamente referencias bibliográficas sobre el tema, a pesar de que ya la población inmigrada femenina era mayoritaria en España, debido, en gran parte, a la inmigración procedente de los países occidentales. Los primeros libros sobre migración extranjera que aparecen en el mercado español obvian, generalmente, la importancia autónoma de las mujeres en el proceso, si no es para tratar el tema muy tangencialmente. Queda también claro que el interés lo despertará la presencia de migración femenina no comunitaria.

Siguiendo la corriente general en el estudio de las migraciones, la primera bibliografía respondería a la necesidad de constatar la realidad estadística. Se recogen los resultados de los primeros procesos de regularización, y se abunda en aspectos de carácter demográfico y sobre la situación familiar. En estos primeros esbozos de la temática sociodemográfica, destacaríamos los trabajos pioneros del Colectivo IOÉ y de Antonio Izquierdo.

Normalmente, el análisis de la variable «sexo» se sitúa en el contexto general del proceso migratorio y formará parte de una variable más, juntamente 
con la edad o el estado civil. Más adelante, veremos como los epígrafes correspondientes a la mujer van llenando los apartados dedicados a prácticas culturales o redes familiares. A raíz del estudio de la importancia de las demandas femeninas de regularización que se dan durante la segunda mitad de los años ochenta, aparece la importancia de la mujer en las redes «ilegales». Pero de los primeros artículos se desprende la idea que sería el reagrupamiento familiar, el papel del género en los modelos de asentamiento y la segunda generación los trazos configuradores de la variante "género» en el futuro de las migraciones.

Más recientemente se continuarán utilizando los datos sociodemográficos como fuente, aunque esta literatura permitirá aportar información sobre la tipologización de la mujer inmigrante desde el ámbito de la sociología en base al análisis de las trayectorias y los proyectos migratorios. Estos análisis, en este sentido, tienden a diversificar y desmontar ciertos prejuicios y estereotipos, y se proponen, en la mayoría de los casos, considerar a la mujer en toda su diversidad como actor migratorio. También se percibe actualmente un creciente esfuerzo por aprovechar nuevos indicadores muy esclarecedores referentes a aspectos como el estado civil de las mujeres, las razones de la emigración o su escolarización.

\section{Bibliografia 3}

La aproximación cuantitativa y demográfica

Colectivo IOÉ (1987). «Empleadas del hogar internas del tercer mundo». En Los inmigrantes en España. Documentación social. Cáritas, 66: 261-265.

- (1998). «Mujeres migrantes en España. Proyectos migratorios y trayectorias de género en la Comunidad de Madrid». OFRIM, p. 11-38.

- (1999). "Aproximació als projectes migratoris de les dones migrants a Espanya» En RoQue, M. Dona i migració a la Mediterrània Occidental. Barcelona: Proa.

Domingo, A. (1998). "La mujer inmigrante tras el velo estadístico». Papers de Demografía, núm. 146.

- (1999). «Visibilitat estadística i població estrangera». En RoQUE, M. Dona i migració a la Mediterrània Occidental. Barcelona: Proa.

Domingo, A.; Brancós, I. (2000). «Población femenina de nacionalidad extranjera en la provincia de Barcelona, 1996». Papers, 60: 305-326.

IZQUIERDO, A. (1992). «El perfil por sexo. La sorpresa de la mujer ilegal». En La inmigración en España: 1980-1990. Madrid: Ministerio de Trabajo y Seguridad Social, p. 154-160.

- (1996). «La situación de la mujer inmigrante en España». En La inmigración inesperada. Madrid: Trotta, p. 117-126.

- (2000). "El proyecto migratorio de los indocumentados según género». Papers, 60: 225-240.

MARRODÁN, M.D. (dir.) (1991). Mujeres del Tercer Mundo en España: modelo migratorio y caracterización sociodemográfica. Madrid: Fundación CIPIE. 


\section{La generalización de la perspectiva cualitativa}

En parte como consecuencia lógica de la dificultad que supone trabajar a partir de datos estadísticos fiables, y en parte como instrumento metodológico para profundizar en el tema, una de las perspectivas más habituales será utilizar el análisis del material empírico obtenido a través de metodología cualitativa, a menudo consistente en el recurso a la entrevista en profundidad y la historia de vida a una muestra más o menos amplia de inmigrantes femeninas. En algunos casos, no sólo se trata de entrevistas a las mujeres inmigrantes, también se recoge el papel de representantes de asociaciones e instituciones involucradas. Éste es uno de los ejes utilizados en numerosos casos por los estudios de la sociología de las migraciones, pero lo será con especial intensidad en el apartado de género.

Esta bibliografía aparecerá, por un lado, en su vertiente metodológica en los trabajos de investigación. En el ámbito de los trabajos sociológicos, destacará por su importancia pionera en aquel momento, el libro de Carlota Solé sobre inmigración femenina en España. Este documento comparativo analiza, a través de la situación, actitudes y opiniones, a las mujeres de tres grandes colectivos: las magrebíes, las africanas y las asiáticas.

La aproximación a las motivaciones, expectativas, autopercepción y valores de las mujeres en el proceso migratorio también se reflejará en formato periodístico. Podemos afirmar que abunda la bibliografía "testimonial» en la que se recogen las vivencias a través de los relatos en los cuales son las propias inmigrantes las que describen su trayectoria migratoria. Así mismo, constatamos que una gran parte de la bibliografía responde a esta perspectiva metodológica, aquí señalamos como ejemplo algunas de las obras que ilustrarían los diferentes tipos de aproximación al tema.

\section{Bibliografia 4}

Selección de tipología de publicaciones sobre migraciones femeninas de carácter cualitativo

Asociación de Mujeres DominiCANAS en EsPaña (1993). Tres mujeres dominicanas en Madrid: sus historias contadas por ellas mismas. Madrid: AMDE. EMBAREK, M. (1995). «Mujeres marroquíes en España. Testimonios orales». En MarTín Muñoz (comp.). Mujeres, Democracia y Desarrollo en el Magreb. Madrid: Ed. Pablo Iglesias, p. 183-188.

FrANZÉ, A. (1998). «Lo que sabía no valía. Trayectoria escolar y construcción de las relaciones entre iguales en la historia de Naima». OFRIM. Suplementos, p. 125-142.

GARCIA, S.; SERnA, M. (1995). A cara descoberta: ser marroquina i viure a Catalunya. Barcelona: Columna.

SÁNCHEZ, S.; BRIGNONI, S. (1993). Dones immigrants: gènere i estrangeria. Barcelona: Institut Català de la Dona.

SolÉ, C. (1994). La mujer inmigrante en España. Madrid: Instituto de la Mujer. 


\section{Contextualización y descripción}

Del mismo modo que la metodología sociodemográfica nos permite comparar la situación de la mujer con los estándares de migración masculina, mucha de la bibliografía formará parte de un tratamiento contextualizador del tema que servirá para alertar sobre aquellos aspectos que caracterizan al colectivo femenino. Se han agrupado, en este epígrafe, tres tipos de materiales, todos ellos tienen en común la perspectiva amplia desde la que tratan el género en las migraciones, sin especificar grupos étnicos, categorías laborales ni líneas temáticas específicas. Unos utilizarán un tratamiento descriptivo que a veces se enmarcará en una perspectiva más amplia sobre inmigración o sobre mujer. Otros recogen el resultado de jornadas y seminarios específicos. Un tercer grupo se concentra en estas problemáticas genéricas en un núcleo urbano determinado.

\section{Bibliografia 5}

\section{Obras de carácter general}

Ajuntament de BarCelona. Consell de les dones de Barcelona (1998). Barcelona: I Congrés de les dones de Barcelona.

DAOLIO, M.A. (1995). «Compromisos solidarios con las mujeres inmigrantes». En Migraciones: tópicos y realidades. Madrid: CCOO, p. 101-104.

- (coord.) (1996). Las mujeres inmigrantes en Andalucia. Madrid: Federación de Mujeres Progresistas.

Masllorens, A. (1995). «Problemes específics de la dona immigrant». En MASLLORENS. Informe sobre la Immigració. Barcelona: Deriva, p. 59-72. Pajares, M. (1998). «La mujer inmigrada». En La inmigración en España. Barcelona: Icaria, p. 173-181.

ROQUERO, E.; RODRÍGUEZ, P. (1996). La diversidad de las mujeres migrantes: el caso de la ciudad de Granada. Madrid: Instituto de la Mujer.

SÁNCHEZ ZeLASKI, S.; BRIGNONI, S. (1993). «Mujer inmigrante: otra cara de la extranjería». Entre jóvenes, 33-34: 41-47.

VV.AA., Ajuntament de Barcelona (1994). I Jornades sobre la Dona Immigrada. Les dones immigrades desafien la seva invisibilitat. Inédito.

\section{El mercado de trabajo: un eje definitivo de segmentación por género}

Probablemente estemos ante uno de los campos que se haya mostrado más prolífico, en cuanto a producción bibliográfica se refiere, en estos últimos tiempos. Varias cuestiones explicarían el creciente interés por los aspectos relacionados con el mercado de trabajo de las mujeres inmigradas. En parte cabe enmarcar este interés como consecuencia de los trabajos generales realizados en la sociología de las migraciones y en la sociología económica. Además, debemos tener en cuenta el hecho de que la ocupación femenina pronto se consolidará como un trabajo marginal, que sufre de unas duras condiciones laborales y que se concentra en actividades de pobre prestigio social. Otro fenómeno que influirá será 
el progresivo incremento de las migraciones económicas de mujeres solas. De este modo, la lógica económica toma protagonismo frente a los análisis referentes a la función de la mujer reagrupada y las redes familiares. Sin que ello signifique que éstas últimas no tengan un papel económico, sino que más bien la diferencia se plantea en el inicio e iniciativa del proceso inmigratorio.

La invisibilidad del colectivo inmigrante femenino se encuentra muy relacionada con el tipo de trabajo que se realiza. Si tenemos en cuenta que el trabajo doméstico y personal, seguido de las ocupaciones en hostelería, ocupan a la mayoría de las mujeres inmigrantes, parece lógico que sea éste el que constituya un foco de atención, y que ya lo comenzara a ser en una primera etapa. La importancia en algunos núcleos urbanos, como es el caso del servicio doméstico en la Comunidad de Madrid, ha hecho que, lógicamente, haya ocupado una gran parte de la atención bibliográfica. Por otro lado, problemáticas relacionadas con trabajos más precarios, como es el caso de la prostitución, todavía no están suficientemente reflejadas bibliográficamente.

A pesar del interés evidente de esta tipología, parece oportuno alertar sobre el riesgo que comporta pasar de estereotipar a la mujer inmigrante de reproductora a productora, y en todo caso mantenerla en un estereotipo marginal. Todavía son pocos los análisis que contemplen el sujeto femenino como agente activo de la cooperación Norte-Sur. En esta última etapa, han comenzado a aparecer publicaciones que analizan el papel de la mujer como actora de su propio proceso, aquella mujer que se desplaza sola como pionera de la migración familiar y que mantiene económicamente a la familia inmigrada. También está especialmente presente aquella proporción de mujeres solteras, viudas o divorciadas que son las mayoritarias en la población activa. En estos casos, la situación de la mujer se analiza desde la vertiente de actora de la red migratoria: en las remesas de las transferencias financieras y como soporte de su propio grupo doméstico.

\section{Bibliografia 6}

\section{El mercado de trabajo}

CACHÓN, L. (1995). «El marco institucional de la discriminación y tipos de inmigrantes en el mercado de trabajo en España». Revista Española de Investigaciones Sociológicas, 69: 105-124.

- (1997). «Segmentación sectorial de los inmigrantes en el mercado de trabajo en España». Cuadernos de Relaciones Laborales, 10: 49-73.

Carmona, S. (2000). «Inmigración y prostitución: el caso del Raval (Barcelona)». Papers, 60: 343-354.

CATARINO, C.; OsO, L. (2000). «La inmigración femenina en Madrid y Lisboa: hacia una etnización del servicio doméstico y de las empresas de limpieza». Papers, 60: 183-207.

CCOO. SECRETARía DE LA MUJER. Guía para las trabajadoras inmigrantes. Madrid: CCOO. 
COLECTIVO IOÉ (1991). Trabajadoras extranjeras de servicio doméstico en Madrid, España. Ginebra: Organización Internacional del Trabajo.

- (1997). «Exploración bibliográfica sobre inserción social y profesional de las mujeres migrantes. Informe sobre España». En La inserción profesional de las mujeres inmigrantes. Madrid: Proyecto ANIMA (Comisión Europea).

CRuells López, E. (1997). Mujeres inmigrantes extracomunitarias en la hostelería de Barcelona. Barcelona: Associació de Dones per la Reinserció Laboral (SURT).

GALLARDO RIVAS, G. (1995). Buscando la vida: dominicanas en el servicio doméstico en Madrid. Santo Domingo: CIPAF-IEPALA.

Herranz Gómez, Y. (1996). Formas de incorporación laboral de la inmigración latinoamericana en Madrid: importancia del contexto de recepción. Madrid: Universidad Autónoma de Madrid. Tesis de doctorado.

- (1997). «Mujeres dominicanas en el servicio doméstico de Pozuelo-Aravaca». Cuadernos de Relaciones Laborales, 10: 75-101.

- (1997). «Transformación del mercado laboral de Madrid y feminización de la inmigración latinoamericana». En MAQUIEIRA, V.; VARA, M.J. (ed.). Género, Clase y Etnia en los nuevos procesos de globalización. Madrid: UAM, p. 171-182.

- (1997). «Problemas de acceso al mercado laboral, integración y redes de solidaridad. El caso de las mujeres dominicanas». Revista de Relaciones Laborales.

- (1998). «Servicio doméstico y feminización de la inmigración en Madrid». Ofrim. Suplementos, p. 65-84.

IZQUIERDO, A. (dir.) (1996). Panorámica general de la inmigración femenina en España y efectos del proceso migratorio sobre el rol y el estatus socio-económico de las trabajadoras extranjeras en España. Madrid: Instituto de la Mujer. Inédito.

Oso CASAS, L. (1998). La migración hacia España de Mujeres Jefas de Hogar. Madrid: Instituto de la Mujer.

SÁNCHEZ MARTín, M.E. (coord.) (1992). Nuestras hermanas del Sur: la inmigración marroqui y el servicio doméstico en Madrid. Madrid: Dirección General de Migraciones. Inédito.

SeCretaría de la DONA DE la CONC (1994). "Dona immigrant i mercat de Treball». Recull Anual sobre immigració. Barcelona: CITE.

SolÉ, C. (1991). Trabajadores extranjeros en Cataluña. ¿Integración o Racismo? Madrid: Centro de Investigaciones Sociológicas. Monografías CIS, núm. 16.

\section{La geografía de las migraciones: lugares de recepción y población de origen}

La importancia que toma desde un primer momento la feminización de algunos colectivos, marcará claramente los temas de las publicaciones. Las primeras a afianzarse serán las mujeres filipinas, que constituirán el colectivo más feminizado, otras, como las marroquíes, conformarán el colectivo más nume- 
roso, aunque, en su caso, es mayoritaria la presencia de efectivos masculinos. A partir de la segunda mitad de los noventa destaca la población de mujeres dominicanas, y también la presencia de peruanas. Este marco favorece la importancia de los artículos sobre población femenina dominicana, marroquí y filipina.

A partir de la segunda mitad de los años noventa, al mismo tiempo que se intensifica la aparición de bibliografía sobre mujeres, ésta comienza a ubicarse en ciertos puntos de la geografía española que coinciden con su importancia creciente. Esta espacialización se da en un doble sentido: por un lado, se concentra en aquellas comunidades autónomas en las que el número de mujeres inmigrantes es más importante (Madrid, Cataluña y Barcelona, Andalucía) y, por otro, se generaliza paulatinamente por toda la geografía española, coincidiendo con la emergencia, al mismo tiempo, de ciertas dinámicas migratorias, y de una especial sensibilización hacia el tema (Navarra, Euskadi, Murcia...).

Esta bibliografía responde a menudo a aspectos relacionados con las problemáticas de un colectivo determinado (como ya hemos dicho, el sector doméstico en Madrid es significativo), también a aspectos relacionados con género y espacio urbano (el papel de la mujer en las redes familiares, como es el caso de estudios en Barcelona sobre la inmigración o el de la mujer en Granada, dada su peculiar caracterización).

Por nacionalidades de origen, las mujeres marroquíes son las que más atención bibliográfica merecen, seguidas de las dominicanas, las filipinas y finalmente diversos grupos nacionales subsaharianos. Los temas tratados también responden a ciertas pautas de cada uno de los colectivos, así, por ejemplo, se da la tendencia a agrupar el tratamiento de las africanas, mientras que las latinoamericanas son tratadas en gran parte desde la perspectiva de las dominicanas. En este último colectivo abunda la literatura sobre el mercado de trabajo, mientras que la trayectoria vital y la familia es más tomada en consideración en el caso de las mujeres marroquíes.

\section{Bibliografia 7}

\section{Mujeres latinoamericanas (especial atención al colectivo dominicano)}

Asociación de Mujeres Dominicanas en España. Dominicanas en España. Madrid: AMDE.

ESCRIVÁ, Á. «¿Empleadas de por vida? Peruanas en el servicio doméstico de Barcelona». Papers, 60: 327-342.

Gallardo RIVAS, G. «Mujeres del sur de Europa: dominicanas en Madrid». La vivencia del racismo. Madrid: IEPALA.

Gregorio GIL, C. (1992). «La participación de las mujeres de América latina y África en los movimientos migratorios a España». SODEPAZ, 9: 31-38.

- (1996). Estudio de la red migratoria del colectivo dominicano en Madrid. Madrid: Dirección General de Migraciones. Inédito. 
- (1998). «Inmigración, identidad de género y choque cultural: el caso de las mujeres dominicanas». OFRIM. Suplementos, p. 161-174.

Gregorio Gil, C.; RamíreZ, A. (2000). «¿En España es diferente...? Mujeres inmigrantes dominicanas y marroquíes». Papers, 60: 257-273.

GALlARDO RIVAS, G. (1995). Buscando la vida: dominicanas en el servicio doméstico en Madrid. Santo Domingo: CIPAF-IEPALA.

Herranz Gómez, Y. (1996). Formas de incorporación laboral de la inmigración latinoamericana en Madrid: importancia del contexto de recepción. Madrid: Universidad Autónoma de Madrid. Tesis de doctorado.

- (1997). «Mujeres dominicanas en el servicio doméstico de Pozuelo-Aravaca». Cuadernos de Relaciones Laborales, 10: 75-101. Madrid.

- (1997). "Transformación del mercado laboral de Madrid y feminización de la inmigración latinoamericana». En MAQUIEIRA, V.; VARA, M.G. Género, Clase y Etnia en los nuevos procesos de globalización. Madrid: Edras, p. 171-182.

- (1997). «Problemas de acceso al mercado laboral, integración y redes de solidaridad: el caso de las mujeres dominicanas en Madrid». Revista de Relaciones Laborales.

Mujeres asiáticas (especial atención al colectivo filipino)

Berges Llobera, M.T. (1993). «La inmigración filipina en la Comunidad de Madrid». En GimÉnez Romero, C. (coord.). Inmigrantes extranjeros en Madrid. Madrid: Imprenta de la Comunidad de Madrid, tomo II, p. 561-619.

Camamala, C. (1994). «Les dones entren a la immigració per la porta de servei. Aproximació etnogràfica al col-lectiu de dones filipines a Barcelona». ICESB. Perspectiva Social, núm. 35: 85-166.

NiETO, G. (1998). «La enseñanza, por vocación... Identidad nacional y mujeres inmigrantes chinas». OFRIM. Suplementos, p. 143-160.

Ribas MateOS, N. (1994).«Origen del proceso emigratorio de la mujer filipina a Cataluña». Papers, 43: 101-114.

- (1996). La heterogeneidad de la integración social: una aplicación a la inmigración extracomunitaria (filipina, gambiana y marroqui) en Cataluña (1985-1996). Bellaterra: Universidad Autónoma de Barcelona. 2 vol. Tesis de doctorado.

- (1999). Las presencias de la inmigración femenina. Un recorrido por Filipinas, Gambia y Marruecos en Cataluña. Barcelona: Icaria.

\section{Mujeres magrebies (especial atención al colectivo marroqui)}

Actis, W. (1995). «Mujeres marroquíes en España. Algunos datos generales». En Martín Muñoz, G. (comp.). Mujeres, Democracia y Desarrollo en el Magreb. Madrid: Ed. Pablo Iglesias, p. 125-130.

Asociación de Trabajadores InMigrantes Marroquíes en España (1996). Informe sobre la mujer marroqui inmigrante en España. Madrid: ATIME. 
Bel, C.; Cebrián, A. (1997). «La mujer en el marco de la inmigración magrebí en España». Anales de Historia contemporánea, núm. 13.

BermúdeZ, M.; Framis, M. (1993). La dona immigrant magribina: primera aproximació i proposta metodològica. Barcelona: Institut Català de la Dona.

CABEllo, E. (1994). «Mujeres emigrantes marroquíes: un caso de segunda generación». En Morales LeZCANo, V. (ed.). El desafio de la inmigración en la España actual: una perspectiva europea. Madrid: UNED, p. 193-198.

Carmona, S. (2000). «Inmigración y prostitución: el caso del Raval (Barcelona)». Papers, 60: 343-354.

Colectivo IOÉ (1994). Marroquins a Catalunya. Barcelona: Proa.

- (1995). Presencia del sur. Marroquies en Cataluña. Madrid: Fundamentos.

EMBAREK, M. (1995). «Mujeres marroquíes en España. Testimonios orales». En Martín Muñoz, G. (comp.). Mujeres, Democracia y Desarrollo en el Magreb. Madrid: Ed. Pablo Iglesias, p. 183-188.

FundaCión Promoción SOCIAL de la CulTura (1994). Mujeres del Magreb: la disparidad de género y perspectivas de integración: informe (Madrid, abril 1994). Madrid: Fundación Promoción Social de la Cultura.

GaRCIA, S.; DE LA SERNA, M. (1995). A cara descoberta: ser marroquina i viure a Catalunya. Barcelona: Columna.

Gregorio Gil, C. (1993). «Mujeres migrantes marroquíes en la CAM». En LÓPEZ, B. y otros. Inmigración magrebi en España. Madrid: Colecciones Mapfre, p. 485.

JiMÉNEZ ILLESCAS, L. (1996). Estudio enfocado al colectivo de mujeres inmigrantes marroquies en España: la mujer de Alhucemas. Madrid: Dirección General de Migraciones. Inédito.

LosADA, T. (1992). «La dona immigrant d'origen magrebí: de la família tradicional a la societat d'acollida». Revista del Col.legi Oficial de Psicòlegs de Catalunya, núm. 4.

- (1993). «La dona immigrant marroquina». DCIDOB, núm. 43. Barcelona.

- (1995). «La mujer inmigrante marroquí en España. Emigración y emancipación». En MARTín MuÑoz, G. (comp.). Mujeres, Democracia y Desarrollo en el Magreb. Madrid: Ed. Pablo Iglesias, p. 131-142.

Morote, M.; Serrano, J.M.; GómeZ, J. (1997). «Mujeres magrebíes en la región de Murcia». Anales de Historia Contemporánea, núm. 13.

MouAlHI, D. (1997). Las migradas magrebies en Cataluña. Área metropolitana de Barcelona: El contexto de origen y las motivaciones de emigración. Tesina de Magister. UAB.

- (2000). «Mujeres musulmanas: estereotipos occidentales versus realidad social». Papers, 60: 291-304.

RAMíREZ, A. (1995). «Marroquíes en España: emigración y emancipación». En Martín Muñoz, G. Mujeres, democracia y desarrollo en el Magreb. Madrid: Fundación Pablo Iglesias. 
- (1996). "La progresiva feminización del colectivo marroquí». En LóPEZ, B. (1996). Atlas de la Inmigración magrebi en España. Universidad Autónoma. Madrid.

- (1997). «El largo camino que lleva a España. Secuencia de las migraciones femeninas marroquíes». Anales de Historia Contemporánea, 13: 69-85.

- (1998). Migraciones, género e Islam: mujeres marroquíes en España. Madrid: Edics. Mundo Árabe e Islámico. Educación y Cultura.

- (1998). «Relacionarse en Madrid: Mujeres, Hombres y asociacionismo marroquí». OFRIM. Suplementos, p. 103-125.

- (1999). "Les dones marroquines, les migracions i el matrimoni». En Roque, M.A. Dona i migració a la Mediterrània occidental. Barcelona: Proa, p. 159-172.

RAMíREZ, E. (1996). «La mujer marroquí». Inmigrantes en España: vidas y experiencias. Madrid: CIS. Monografías, 147: 49-52.

RiBAS MATEOS, N. (1996). La heterogeneidad de la integración social: una aplicación a la inmigración extracomunitaria (filipina, gambiana y marroquí) en Cataluña (1985-1996). Bellaterra: Universitat Autònoma de Barcelona. 2 vol. Tesis de doctorado.

- (1999). Las presencias de la inmigración femenina. Un recorrido por Filipinas, Gambia y Marruecos en Cataluña. Barcelona: Icaria.

Rojo, A. (1997). Mujeres marroquies: trayectorias y experiencias vitales. Madrid: Universidad Complutense de Madrid. Tesis de doctorado.

SAYD, Y. (1992). La mujer inmigrante en Cataluña: mujeres marroquies con problemas. Barcelona: Comissionat de l'Alcaldia per a Defensa dels drets civils. TROYANO, J.F. (dir.) (1994). Estudio de la inmigración magrebi en la provincia de Málaga: especial atención a la mujer. Málaga: CITE.

Mujeres africanas

Gregorio GiL, C. (1992). «La participación de las mujeres de América latina y África en los movimientos migratorios a España». SODEPAZ, núm. 31-38.

JABARDO, M. (1998). «La inmigración femenina africana y la construcción social de la "Africanidad"».OFRIM. Suplemento, p. 175-187.

Kaplan, A. (1998). De Senegambia a Cataluña. Procesos de aculturación e integración social. Premio Dr. Rogeli Doucastella. Barcelona: Fundació "la Caixa"».

RiBAS MATEOS, N. (1996). La heterogeneidad de la integración social: una aplicación a la inmigración extracomunitaria (filipina, gambiana y marroquí) en Cataluña (1985-1996). Bellaterra: Universitat Autònoma de Barcelona. 2 vol. Tesis de doctorado.

- (1999). Las presencias de la inmigración femenina. Un recorrido por Filipinas, Gambia y Marruecos en Cataluña. Barcelona: Icaria.

SIPI, R. (1997). Las mujeres africanas. Incansables creadoras de estrategias para la vida. L'Hospitalet: Mey. 


\section{Género e inmigración: tipologías y perspectivas bibliográficas}

Hasta aquí la bibliografía analizada respondía en gran parte a los principales aspectos que se han ido perfilando: mercado de trabajo, tipología por países de origen... A partir de este recorrido, podríamos establecer la siguiente tipología: fuentes descriptivas o de carácter informativo; bibliografía de investigación y teórica y, finalmente, documentación empírica y operacional. Las tres tipologías responderían a finalidades diversas (atendiendo a trabajos universitarios, demandas de administraciones...), aunque hoy por hoy y en parte debido a la novedad, en parte a un cierto desconocimiento, se encuentran poco diferenciadas en el campo de análisis que nos ocupa, y esto supone que a menudo se corre el peligro de formular lecturas poco precisas. Paralelamente, asistimos a una diversificación y a una segmentación de los puntos de vista desde los que en este tema se tratan. En este último apartado mencionaremos aquellas publicaciones que han mostrado como principal interés el de incidir en los aspectos en los que ser mujer condiciona de manera importante la experiencia migratoria, es decir, los que la hacen distintiva y autónoma a partir de ciertas prácticas propias. La perspectiva del análisis de las redes familiares como conjunto no ha sido contemplada, a pesar que de ellas evidentemente se desprendan no pocos aspectos relacionados con la mujer inmigrante.

Una de las propuestas más atractivas es la que responde a la necesidad de completar el análisis del país de acogida con la contextualización de partida en las sociedades emisoras. En las publicaciones que aportan información sobre este contexto la mujer es analizada como elemento de relación entre una y otra cultura y también desde sus propias expectativas. La perspectiva meramente migratoria se enriquece desde la vivencia cultural y social que se arrastra, y nos hace entender mejor una situación suficientemente complicada para reducirla a la mera asimilización en nuestras sociedades de acogida. De ahí que temas colaterales, como pueden ser la vivencia de las prácticas culturales, la relación con la religión y, en definitiva, la situación social y jurídica de las mujeres en los países de origen, conforme poco a poco una bibliografía complementaria que va tomando cuerpo. Debemos estar atentos también a la importancia de las publicaciones sobre la mujer en la sociedad de origen, y es de esperar que cada vez más aparezca bibliografía que analice las consecuencias del proceso migratorio en el contexto de partida, y los cambios que este proceso produce en la situación de la mujer. Por otro lado, resulta significativa la repercusión que paulatinamente están observando en el mercado editorial español las mujeres de países que coinciden con los lugares de origen de parte de la inmigración presente. Se trata de un campo que se ve cada vez más enriquecido por una generación de mujeres escritoras que aportan su especial sensibilidad hacia la problemática de la mujer. Destacamos en este apartado el caso del mundo árabe. 
Bibliografía 8

Selección de publicaciones en español sobre mujeres en el mundo árabe (1995-1999)

Амо, M. (ed.) (1997). El imaginario, la referencia y la diferencia: siete estudios acerca de la mujer árabe. Granada.

BELARBI, A.; MERNISSI, F. y otros (1996). La mujer en la otra orilla. Barcelona: Flor del Viento.

BORRÀs, A.; MERNISSI, S. (ed.) (1998). El islam jurídico y Europa. Barcelona: Icaria.

DELAUNOY, G. (1996). La mujer en el Islam: la situación de la mujer musulmana en los países mediterráneos de Oriente Próximo y del Magreb. Luxemburgo: Parlamento Europeo.

Esteva, J. (1998). Mil y una voces. Madrid: El País.

GHeZALI, S. (1999). Los amantes de Sherezade. Barcelona: Martínez Roca.

HANUnE, L. (1997). La otra cara de Argelia. Madrid: VOSA.

HART, U. (1998). Tras la puerta del patio: la vida cotidiana de las mujeres rifeñas. Melilla: Ciudad Autónoma de Melilla. Servicio de Publicaciones.

Heller, E.; MosBahi, H. (1995). Tras los velos del islam. Erotismo y sexualidad en la cultura árabe. Barcelona: Herder.

JULIANO, D. (1998). La causa saharaui y las mujeres. Barcelona: Icaria.

Martín Muñoz, G. (1995). Mujeres, Democracia y Desarrollo en el Magreb. Madrid: Pablo Iglesias.

Mernissi, F. (1991). Marruecos a través de sus mujeres. Madrid: Ediciones del Oriente y del Mediterráneo.

- (1995). El poder olvidado: Las mujeres ante un Islam en cambio. Barcelona: Icaria.

- (1995). Sueños en el umbral: memorias de una niña del harén. Barcelona: Muchnik.

Moga Romero, V.; Rachid Ahmed, R. (ed.) (1998). Mujer tamazight y fronteras culturales: estudios acerca del status de la mujer bereber y de sus condicionamientos culturales. Melilla: Ciudad Autónoma de Melilla. Servicio de Publicaciones.

NiLUfER, G. (1995). Musulmanas y modernas: velo y civilización en Turquía. Madrid: Talasa.

PARLAMENTO EuROPEO (1998). Nota sobre la situación de las mujeres en Argelia. Dirección General de Estudios. Dirección General de Comisiones y Delegaciones.

RoQUe, M.A. (1999). «Religió popular, espai actiu de la dona magrebina». En RoQue, M.A. (dir.). Dones i migració a la Mediterrània occidental. Barcelona: Proa.

El SaAdaWI, N. (1998). La mujer que buscaba. Barcelona: Martínez Roca. 
Desde una situación de colectivo especialmente sensible a la triple discriminación étnica, por clase social y por género, se impone una cierta sensibilidad hacia el análisis de las imágenes y representaciones, de una parte, y hacia las políticas públicas, de otra. El papel de la mujer en la integración del colectivo inmigrante, la importancia de la visibilidad social y la representación cultural, así como el peligro de estigmatización de la figura marginal de la mujer inmigrante aparecen todos ellos como temas cada vez más recurrentes. En este sentido, el tratamiento de su papel en los medios en estos últimos años y la relativa abundancia de noticias que hacen referencia al trabajo precario y al de las tareas en el servicio doméstico, corren el riesgo de reforzar e incidir en papeles estereotipados tradicionalmente.

\section{Selección de titulares de prensa sobre la mujer inmigrante (1995-1998)}

«Les dones immigrants trenquen tòpics». Presència. Noviembre de 1998.

«El Tráfico de mujeres extranjeras se ha duplicado en España». El Mundo. 11 de mayo de 1998.

«175 mujeres magrebíes harán de agentes de salud de inmigrantes». El Periódico. 8 de abril de 1997.

«Modernas esclavas domésticas: explotación de empleadas dominicanas y peruanas». El Periódico. 21 de julio de 1997.

«Las niñas musulmanas de Girona vuelven al colegio el próximo lunes». El Pais. 13 de diciembre de 1997.

«Les dones immigrants acaparen el 30\% dels permisos de treball». Diari de Girona. 21 de agosto de 1997.

«El boom de las mujeres de la limpieza». El Periódico. 28 de diciembre de 1997. «La tercera parte de los inmigrantes en España, son mujeres». El Mundo. 23 de agosto de 1996.

«La igualdad de la mujer en África ayudaría a frenar las migraciones». El País. 16 de octubre de 1996.

«Entrevista a una trabajadora marroquí del servicio doméstico». $A B C .15$ de diciembre de 1996.

«Las que tienen que servir». Diario 16. 6 de febrero de 1996.

«Valencia abre un centro universitario para muchachas de los Emiratos Árabes Unidos». La Vanguardia. 12 de enero de 1996.

«La mujer ha sido siempre la gran ausente en la historia de la emigración». Última hora. 20 de febrero de 1996.

«Mercado de novicias: la dura experiencia de las extranjeras en conventos españoles». El Mundo. 23 de mayo de 1996.

«Mujeres por la puerta de servicio». El País. 8 de enero de 1995.

"Les dones immigrants tindran un estatut propi abans de la primavera». Avui. 3 de enero de 1995.

«Esclavas de Alá. Un libro relata la difícil adaptación de las inmigrantes marroquíes en Cataluña». El Periódico. 24 de marzo de 1995. 
En el campo de la literatura que podríamos calificar con finalidad «operacional», dos debates son de actualidad a nivel de migraciones: el debate legislativo y el que hace referencia a la provisión de políticas sociales. Ambos afectan de pleno a las políticas públicas, que permanecen sin embargo indefinidas respecto a su tratamiento por género. En todo caso, parece que existe un interés en el tratamiento de la capacidad asistencial, sobretodo respecto a dimensiones como la sanitaria. También existen aspectos más ligados a la integración del colectivo (formación, mediación) que apuntan el interés de algunas de las publicaciones. Respecto a la dimensión legislativa, el estudio de la mujer y del derecho en su dimensión migración y género hace referencia a aspectos muy relacionados con la familia (matrimonio, poligamia, repudio, herencia, filiación, reagrupamiento familiar...), pero permanece sin estudiarse el papel autónomo de la mujer en estos procesos fundamentales en los que a menudo es la protagonista. Otras dimensiones como la asociativa, la segunda generación o la vivencia intercultural también se encuentran entre los aspectos poco reflejados en la bibliografía disponible.

Finalmente debemos mencionar, por su importante presencia en muchos de los ensayos, el esfuerzo en justificar teóricamente el género como categoría de análisis en el estudio de las migraciones. En este sentido, se ha trabajado en el campo teórico y en el de las identidades y el género, sobre todo desde la historia y la antropología.

\section{Bibliografia 9}

\section{Políticas sociales}

Associació de Planificació Familiar de Catalunya i Balears (1997). Programa de intercambio cultural, prevención y promoción de la salud afectivo-sexual y reproductiva en mujeres y familias magrebies, 1997: evaluación y resultados.

Aubarell, G.; Ribas, N. (1999). "Quines respostes? Polítiques en clau de gènere». En RoQue, M.A. Dona i migració a la Mediterrània Occidental. Barcelona: Proa.

DíAz, B. (1997). Del acercamiento a la Acción: promoción de la salud entre los/las inmigrantes extranjeros/as. Bilbao: EDE.

GARCÍA CASTAÑO, F.J. (coord.) (1994). La escolarización de niñas y niños inmigrantes en el sistema educativo español. Granada: Laboratorio de Antropología, Universidad de Granada.

Ribas, N. (coord.); Alarcón, A.; Gibert, F.; Parella, S. (2000). «Políticas de formación para mujeres inmigrantes. El caso de la ciudad de Barcelona». Papers, 60: 365-379.

- (1998). «Política Social: Inmigración y género en la Comunidad de Madrid». OFRIM. Suplementos, p. 85-102.

TAROZZY, A. (1999). Las mujeres como intermediarias culturales en Paloma de Villota. Globalización y Género. Madrid: Síntesis. Economía. Serie: Actualidad, p. 241-258. 
Representaciones e integración

BARANDICA, A. (1998). «Mujer inmigrada». SOS Racisme. Informe Anual 1998 sobre el racismo en el estado español, p. 147-151.

Bedoya, M.H. (2000). «Mujer extranjera: una doble exclusión. Influencia de la ley de extranjería sobre las mujeres inmigrantes». Papers, 60: 241-256.

Colectivo IOÉ (1997). Procesos de inserción y exclusión social de las mujeres inmigrantes no comunitarias. Madrid: Instituto de la Mujer. Inédito.

Díaz Aguado, Ma J.; Segura García, M.P.; Martínez Arias, R.; Royo GARCÍA, P.; FERRÁNDIZ, P. (1995). Las mujeres inmigrantes y su integración social. Madrid: Instituto de la Mujer.

Gallardo Rivas, G. "La vivencia de la intolerancia». Mujeres en Acción (1). Santiago.

Gregorio GiL, C. (1996). «El proceso de integración de las mujeres inmigrantes». En AGUADO, M.J. y otros (1996). Las mujeres inmigrantes y su integración social. Madrid: Ministerio de Asuntos Sociales. Instituto de la Mujer.

Juliano, D. (1994). Pobres mujeres o mujeres pobres en Extranjeros en el paraiso. Barcelona: Virus, p. 43-52.

MoreT, Ll.; MorenO, M. (1993). «Mujeres inmigrantes. Talleres para la integración». Entre jóvenes, 33-34: 48-49.

Nash, M. (1999). "Construcció social de la dona estrangera». En RoQUe, M.À. Dona i migració a la Mediterrània Occidental. Barcelona: Proa.

SANTOS, L. (1999). "Incidència del marc jurídic en la condició de les dones immigrades a Espanya». En RoQUe, M.A. Dona i migració a la Mediterrània Occidental. Barcelona: Proa.

SiPI, R. (2000). «Las asociaciones de mujeres: ¿agentes de integración social?». Papers, 60: 355-364.

Solé, C. (2000). «Inmigración interior e inmigración exterior». Papers, 60: 211-224.

SOS RACISMO (1999). "La Mujer inmigrada». Informe anual sobre el racismo en el estado español. Barcelona: Icària, p. 189-198.

VIVES, N. (1998). "La mujer inmigrada». Conferencia europea ciudades por los derechos humanos. Estocolmo, 10-12 junio, 1998. Inédito.

Identidad y sistemas de género

GREGORIO GIL, C. (1998). La migración femenina y su impacto en las relaciones de género. Madrid: Narcea.

- (1999). "Los movimientos migratorios del sur al norte como procesos de género». En DE VillotA, P. Globalización y Género. Madrid: Sintesis. Economía. Serie: Actualidad, p. 259-266.

Juliano, D. (1993). «Inmigración y situación de la mujer». En Diez, M. (coord.). Sistemas de género y construcción de la desigualdad. Actas del VI Congreso Español de Antropología, p. 13-25. 
- (1993). "Género, Inmigración e Identidad». En Las Minorías Étnicas. Barcelona, p. 55-74.

- (1996). «Las mujeres inmigrantes, un plus de extranjeridad». En KaPLAN, A. (coord.). Procesos migratorios y relaciones interétnicas. VII Simposio del VII Congreso de Antropología y Federación de Asociación de Antropología del estado español, p. 61-70.

- (1998). Las que saben, subculturas de mujeres. Madrid: Horas y horas. Col. Cuadernos inacabados.

- (1999). «Mobilitat espacial de gènere». En Roque, M.A. Dona i migració a la Mediterrània Occidental. Barcelona: Proa.

LAMELA, C. (1999). «Relaciones y desigualdades de género como mecanismos de selección en los procesos migratorios». Migraciones, 6: 105-127.

RiBAS, N. (1999). Las presencias de la inmigración femenina. Un recorrido por Filipinas, Gambia y Marruecos en Cataluña. Barcelona: Icaria.

Roque, M.A. (dir.) (1999). Dona i migració a la Mediterrània Occidental. Barcelona: Proa.

SolÉ, C. (1999). «La immigració femenina en l’era de la globalització». En Roque, M.A. Dona i migració a la Mediterrània Occidental. Barcelona: Proa.

Varona, M.; Daolio, N. (1994). Inmigración en España: femenino y plural. Madrid: Federación de Mujeres Progresistas. 